\title{
Tuning the Morphological Properties of Cellulose Aerogels: An Investigation of Salt-Mediated Preparation
}

\section{Prakash Parajuli}

Texas Tech University

\section{Sanjit Acharya}

Texas Tech University

Julia Shamshina

Texas Tech University

Noureddine Abidi ( $\nabla$ noureddine.abidi@ttu.edu )

Texas Tech University https://orcid.org/0000-0001-5642-6332

\section{Research Article}

Keywords: Cellulose aerogels, salts, cationic radii, morphology, specific surface area, porosity

Posted Date: April 6th, 2021

DOl: https://doi.org/10.21203/rs.3.rs-333138/v1

License: (c) (i) This work is licensed under a Creative Commons Attribution 4.0 International License. Read Full License 


\section{Abstract}

In this study, alkali and alkaline earth metal chlorides with different cationic radii ( $\mathrm{LiCl}, \mathrm{NaCl}$, and $\mathrm{KCl}$, $\mathrm{MgCl}$, and $\mathrm{CaCl} 2$ ) were used to gain insight into the behavior of cellulose solutions in the presence of salts. The specific focus of the study was evaluation of the effect of salts' addition on the sol-gel transition of the cellulose solutions and on their ability to form monoliths, as well as evaluation of the morphology (e.g., specific surface area, pore characteristics, and microstructure) of aerocelluloses prepared from these solutions. The effect of the salt addition on the sol-gel transition of cellulose solutions was studied using rheology, and morphology of resultant aerogels was evaluated by Scanning Electron Microscopy (SEM) and Brunauer-Emmett-Teller (BET) analysis, while the salt influence on the aerocelluloses' crystalline structure and thermal stability was evaluated using powder X-Ray Diffraction (pXRD) and Thermogravimetric Analysis (TGA), respectively. The study revealed that the effect of salts' addition was dependent on the component ions and their concentration. The addition of salts in the amount below certain concentration limit significantly improved the ability of the cellulose solutions to form monoliths and reduced the sol-gel transition time. Salts of lower cationic radii had a greater effect on gelation. However, excessive amount of salts resulted in the formation of fragile monoliths or no formation of gels at all. Analysis of surface morphology demonstrated that the addition of salts resulted in a significant increase in porosity and specific surface area, with salts of lower cationic radii leading to aerogels with much larger ( 1.5 and 1.6-fold for $\mathrm{LiCl}$ and $\mathrm{MgCl} 2$, respectively) specific surface area compared to aerocelluloses prepared with no added salt. Thus, by adding the appropriate salt into the cellulose solution prior to gelation, the properties of aerocelluloses that control material's performance (specific surface area, density, and porosity) could be tailored for a specific application.

\section{Introduction}

Cellulose aerogels (aerocelluloses) are prepared by replacing the solvent inside cellulose gels with air, creating versatile porous materials that can accommodate gas within their pores (Budtova and Navard 2016; Ganesan et al. 2018b; Long et al. 2018). Due to the attractive properties of cellulose such as renewability, biocompatibility, biodegradability, and chemical stability, and important material characteristics of aerogels such as high specific surface area, low density, and high porosity (Korhonen et al. 2011), aerocelluloses are used for a wide range of applications. The products based on aerocelluloses range from high-value products in pharmaceutical and biotech industries (e.g., drug delivery vehicles, cell storage/growth devices, tissue engineering scaffolds (Pircher et al. 2015; Chin et al. 2016; Soorbaghi et al. 2019)) to medium- or low-value products (e.g., adsorbents (Dassanayake et al. 2016), oil/water separation agents (Liao et al. 2016), chromatographic systems (Luo and Zhang 2010), catalysts (Schestakow et al. 2016b), heat insulation materials (Lazzari et al. 2019), metal nanoparticle/metal oxide carriers (Wan et al. 2016; Tian et al. 2017), and energy absorbers (Li et al. 2018)). For all these applications, the specific surface area, porosity and pore size distribution are undoubtedly the most meaningful morphological characteristics of the materials, as they define the product performance. Thus, the ability to control these intricate aerocelluloses' features is of particular interest. 
Properties of aerocelluloses can be tailored by altering different factors or conditions in each step of their preparation: the polymer's dissolution, regeneration (gel formation), and drying. For example, the type of solvent system used to dissolve cellulose significantly impacts the morphology of aerocelluloses (Pircher et al. 2016), because of the difference in the arrangement of the cellulose chains in these diverse solvent systems. Similarly, altering the morphology of aerocelluloses could be achieved using various additives (e.g., porogen particles (Santos-Rosales et al. 2019), paraffin spheres (Pircher et al. 2015), oil droplets (Ganesan et al. 2016), and surfactants (Ganesan et al. 2018a) to cellulose solutions prior to gel formation. In turn, antisolvents used during cellulose regeneration (Schestakow et al. 2016a) and drying conditions such as supercritical drying, fast- or slow-freezing lyophilization also considerably affect internal aerocelluloses' structure (Buchtová and Budtova 2016).

While studies regarding the effects of various factors on the aerocellulose properties have been carried out, there is no systematic study on the effect of the use of inorganic salt additives on the sol-gel transition of the cellulose solution and the morphology of the resulting aerocelluloses' structure. Indeed, understanding the interaction between inorganic salts and cellulose is not inconsequential. It helps discover the mechanistic role of salt in controlling rheological properties of cellulose solutions, manipulating the physicochemical (including morphological) properties of subsequently regenerated cellulose, and better controlling the conversion of cellulose solutions into useful value-added products (Zhang et al. 2019).

A handful of studies have been reported on the ability of inorganic salts to alter the properties of cellulose solutions resulting in a subsequent change of aerogel properties. Wei and Wang studied the effect of inorganic salts on the gelation of cellulose solution (Wei and Wang 2013). They reported incremental increase in the gelation rate with the salt dosage and in the order $\mathrm{K}^{+}>\mathrm{Na}^{+}>\mathrm{Li}^{+}$for salts cations, and $\mathrm{C} \Gamma>$ $\mathrm{Br}^{-}>\mathrm{NO}^{-}$for anions. Similarly, Laka et al. reported that cations of inorganic salts promoted while anions hindered cellulose gel formation, and that the effect was dependent on the metal valency and salt concentration (Laka et al. 2001). Tokuyasu et al. reported that cellulose pretreatment with calcium chloride $\left(\mathrm{CaCl}_{2}\right)$ increased the surface area of aerogels (Tokuyasu et al. 2008). It has also been shown that trivalent inorganic salts were more effective in degrading polysaccharide molecules, followed by divalent, and monovalent salts (Liu et al. 2009; Kang et al. 2013). Phan-Xuan et al. studied the effect of the valences of the ions on the aggregation behavior and colloidal stability of aqueous cellulose nanocrystals (CNCs) and determined that the salts of multivalent (divalent and trivalent) ions were more effective in inducing CNC aggregation than those of monovalent ions (Phan-Xuan et al. 2016).

In our previous study, we investigated the effect of the addition of sodium chloride $(\mathrm{NaCl})$ salt on aerocellulose properties and found that the addition of $5 \mathrm{wt}$.\% of $\mathrm{NaCl}$ resulted in an increase of the specific surface area by $\sim 2$-fold, and a slight increase in the porosity of cellulose aerogels (Parajuli et al. 2020). In this work, we hypothesized that the addition of various inorganic salts (mono- and divalent, of different cationic radii) would affect the sol-gel transition of cellulose solutions, and, therefore, provide the opportunity to tune the microarchitecture (specific surface area, pore size, total pore volume, and pore 
size distribution) of the resulting aerocelluloses in a predictable manner, with a microstructure of aerocelluloses being a function of the salt's cation.

In this paper, we report a systematic study of the effect of monovalent $(\mathrm{LiCl}, \mathrm{NaCl}$, and $\mathrm{KCl})$ and divalent salts $\left(\mathrm{CaCl}_{2}\right.$ and $\left.\mathrm{MgCl}_{2}\right)$ on the specific surface area, pore characteristics, and other microstructural attributes of cellulose aerogels. We also discuss the effect of salt addition on the sol-gel transition of cellulose solutions which, we believe, has a significant impact on the physicochemical properties of aerocelluloses.

\section{Experimental}

\section{Materials}

Microcrystalline cellulose (MCC) (with degree of polymerization (DP) 180) (Avicel ( PH 102) was purchased from FMC Biopolymer (Newark, DE, USA). Sulfuric acid $\left(\mathrm{H}_{2} \mathrm{SO}_{4}, \geq 95 \%\right.$ ), sodium hydroxide pellets $(\mathrm{NaOH}, \geq 98 \%)$, and powdered inorganic salts - sodium chloride $(\mathrm{NaCl})$, potassium chloride $(\mathrm{KCl})$, lithium chloride $(\mathrm{LiCl})$, calcium chloride $\left(\mathrm{CaCl}_{2}\right)$, and magnesium chloride $\left(\mathrm{MgCl}_{2}\right)$ were purchased from Sigma Aldrich (Saint Louis, MO, USA) and used as received. Acetone ( $\geq 98 \%$ ) was purchased from Fisher Scientific (Pittsburgh, PA, USA) and used as received. Compressed $\mathrm{CO}_{2}$ (Bone Dry 3.0) was purchased from Airgas (Ft. Worth, TX, USA). Deionized (DI) water was obtained from AquaOne (Amarillo, TX, USA).

Methods

\section{Preparation of MCC Solutions}

MCC was used as a precursor for aerocellulose preparation. Cellulose solutions ( 5 wt.\% cellulose) were prepared as followed. First, $\mathrm{NaOH}_{\mathrm{aq}}$ was prepared by mixing $7.6 \mathrm{~g} \mathrm{NaOH}$ (solid) in $37.4 \mathrm{~mL}$ DI water and pre-cooled at $-12{ }^{\circ} \mathrm{C}$ for $2 \mathrm{~h}$. Simultaneously, MCC dispersion was prepared by mixing $5 \mathrm{~g}$ of MCC powder in $50 \mathrm{~mL}$ water, and also pre-cooled at $5{ }^{\circ} \mathrm{C}$ for $2 \mathrm{~h}$. Then, these two solutions were mixed and stirred at 500 RPM, to result in $\mathrm{NaOH}_{\mathrm{aq}}$-cellulose solution with an overall concentration of $7.6 \mathrm{wt}$.\% $\mathrm{NaOH}$, and 5 wt.\% MCC. The resultant translucent solution was stored at $-12{ }^{\circ} \mathrm{C}$ for $1 \mathrm{~h}$ while stirring every $5 \mathrm{~min}$ for 30 s. Exact amounts of solid salts $\left(\mathrm{LiCl}, \mathrm{NaCl}, \mathrm{KCl}, \mathrm{MgCl}_{2}\right.$, and $\left.\mathrm{CaCl}_{2}\right)$ were added into the fixed volume of the $\mathrm{NaOH}_{\mathrm{aq}}$-cellulose solution to prepare solutions of different salt concentrations (w/w), namely, 0 (control), $0.5,1,3,5,7$, and $10 \mathrm{wt}$. , and stirred at $300 \mathrm{RPM}$ at $5^{\circ} \mathrm{C}$ for $5 \mathrm{~min}$.

Rheological properties of the cellulose solution

The rheological properties of cellulose solutions with no salt added (control) and with $0.5 \mathrm{wt} . \%$ salts were measured to investigate the effect of salts on the sol-gel transition of cellulose solutions using a rheometer with a $40 \mathrm{~mm}$ circular plate geometry and a Peltier temperature control system (AR 2000EX, TA Instruments, New Castle, DE, USA). A small volume (ca. $5 \mathrm{~mL}$ ) of the solution was used for the measurement, and the rest was used for aerogel preparation. Two types of measurements, time sweep 
test and temperature sweep test, were performed according to the previously reported method with slight modifications (Oğuz and Ege 2018). The time sweep test was performed at a constant temperature of 20 ${ }^{\circ} \mathrm{C}$ and an angular frequency of $6.28 \mathrm{rad} / \mathrm{s}$. The temperature sweep test was performed at an angular frequency of $6.28 \mathrm{rad} / \mathrm{s}$ in the temperature range of $20-40{ }^{\circ} \mathrm{C}$. Dynamic viscoelastic parameters, the shear storage modulus $\left(G^{\prime}\right)$ and loss modulus $\left(G^{\prime \prime}\right)$, were measured as a function of time $(t, s)$ and temperature $\left(\mathrm{T},{ }^{\circ} \mathrm{C}\right)$ to evaluate the sol-gel transition behavior of cellulose solutions in the presence of different salts. The point of gelation was taken when $\mathrm{G}^{\prime}=\mathrm{G}^{\prime \prime}$ (Cai and Zhang 2006).

\section{Polarized Light Microscopy}

Polarized light microscopy (PLM) images of cellulose solutions and cellulose/salt solutions (0.5 wt.\%) were recorded using a polarizing light microscope with the NIS-Elements Imaging Platform (ECLIPSE LV 100, Nikon Instruments, Melville, NY, USA).

\section{Preparation of Aerogels}

Cellulose aerogels ( $5 \mathrm{wt} . \%$ cellulose) were prepared using the sol-gel-drying route using the approach reported previously (Dassanayake et al. 2016). The pure cellulose and cellulose/salt solutions (see above) were poured into $10 \mathrm{~mL}$ cylindrical vials, capped with parafilm and subsequently gelled at $50{ }^{\circ} \mathrm{C}$ for $2 \mathrm{~h}$ to form a solid gelled mass. The resultant cylindrical gels were regenerated and washed in DI water until the initially yellow hydrogels became completely white. DI water was exchanged every 30 min throughout the day (ca. 15-20 times). After that, the regenerated hydrogels were neutralized in $0.1 \mathrm{M}$ $\mathrm{H}_{2} \mathrm{SO}_{4}$ for $24 \mathrm{~h}$. Afterward, the cellulose hydrogels were successively rinsed with DI water several times (ca. 10 - 15 times) before supercritical drying.

\section{Supercritical drying}

The supercritical drying process was accomplished using Critical Point Dryer (SPI-Dry jumbo, SPT Supplies, West Chester, PA, USA) equipped with a water jacket for heating and cooling following the protocol described previously (Gavillon and Budtova 2008). Aerogel precursors were prepared by replacing the water inside the hydrogel with acetone. Cellulose hydrogels formed by regenerating cellulose solutions were immersed in pure acetone, and acetone was exchanged every two hours throughout the day for four days to ensure that water inside hydrogels was completely replaced by acetone. Vials with acetone-filled hydrogels were placed into the chamber of the critical point dryer filled with liquid $\mathrm{CO}_{2}$ and kept immersed for $48 \mathrm{~h}$ with $\mathrm{CO}_{2}$ flushing every $30 \mathrm{~min}$. After $48 \mathrm{~h}$, the temperature was set above the critical points of $\mathrm{CO}_{2}$. After the required temperature and pressure $(1 \mathrm{~L}$ autoclave, 80 atm, $35^{\circ} \mathrm{C}$ ) (Gavillon and Budtova 2008) were reached, the dryer was slowly depressurized, and cellulose aerogels were recovered from the chamber. Aerogels developed with $\mathrm{LiCl}, \mathrm{NaCl}, \mathrm{KCl}, \mathrm{MgCl}_{2}$, and $\mathrm{CaCl}_{2}$ were labeled as ACel-LiCl, ACel- $\mathrm{NaCl}, \mathrm{ACel}-\mathrm{KCl}, \mathrm{ACel}-\mathrm{MgCl}_{2}$, and $\mathrm{ACel}-\mathrm{CaCl}_{2}$, respectively, whereas the aerogel without any salt was labeled as 'control'. Aerogels were prepared in triplicates for each salt of every concentration. 
Material characterization

Density and Porosity Determination

Geometric dimensions of the aerocelluloses were measured using a digital caliper, whereas the weight was determined gravimetrically. The density of the monoliths was determined using their geometric dimensions and weight values. The porosity was calculated using the following equation (Sehaqui et al. 2011): see equation 1 in the supplementary files.

Where, $\rho_{a}=$ density of aerogels $\left(\mathrm{g} / \mathrm{cm}^{3}\right), \rho_{\mathrm{c}}=$ density of cellulose $\left(\mathrm{g} / \mathrm{cm}^{3}\right), \rho_{\mathrm{a}} / \rho_{\mathrm{c}}=$ relative density

Surface area and pore characteristics analysis

The Brunauer-Emmet-Teller (BET) surface area $\left(\mathrm{S}_{\mathrm{BET}}\right)$, total pore volume, and the pore characteristics of aerogels were determined from $\mathrm{N}_{2}$ adsorption-desorption isotherms collected using surface area analyzer (Gemini VII 2390, Micromeritics, Norcross, GA, USA) at $-196^{\circ} \mathrm{C}$ in a liquid nitrogen environment. Prior to measurements, each sample was degassed at $120^{\circ} \mathrm{C}$ for $18 \mathrm{~h}$ under a continuous flow of $\mathrm{N}_{2}$. The surface area was evaluated using the BET method (Brunauer et al. 1938), while the cumulative pore volume and the pore size distribution were determined using Barret-Joyner-Halendar (BJH) method (Barrett et al. 1951).

\section{Surface Morphology}

The morphology of aerocelluloses was characterized using a field emission scanning electron microscope (FESEM) (S/N 4300, Hitachi, Chiyoda, Tokyo, Japan). Cellulose aerogel monoliths were cut open with a sharp blade to reveal their internal structure and a small piece was fixed onto the sample holder with double-sided carbon tape. The samples were coated by iridium of 2-3 nm thickness and images were recorded using the microscope at $5 \mathrm{kV}$ accelerating voltage. The images were analyzed using Quartz PCl Imaging software (Version 8, Quartz Imaging Corp., Vancouver, Canada) (https://www.quartzimaging.com/pci-microscope-imaging-software.html).

\section{Crystallinity}

The crystalline structures were identified using the powder X-ray diffraction ( $p X R D$ ) technique on SmartLab system (HD 2711N, Rigaku Corp., Tokyo, Japan) using CuKa radiation $\left(\lambda=1.54 \mathrm{~A}^{\circ}\right.$ ) generated at a voltage of $40 \mathrm{kV}$, and current of $44 \mathrm{~mA}$ at a scan rate of $1^{\circ} / \mathrm{min}$, from $5^{\circ} 2 \Theta$ to $50^{\circ} 2 \Theta$. Samples were placed on a glass slide holder and the diffractogram of the empty glass slide was first recorded and subtracted from the diffractogram of the sample. The crystallinity index $(\mathrm{Cl})$ was calculated using the following equation (Segal et al. 1959; Nam et al. 2016): see equation 2 in the supplementary files.

Where, $I_{t}$ represents the intensity of the $\left(\begin{array}{ll}0 & 2\end{array}\right)$ peak at $2 \theta=21.7^{\circ}$, while la represents the amorphous intensity of the peak at $2 \theta=16^{\circ}$ as reported previously for cellulose II (Nam et al. 2016). 
Similarly, the crystallite size was calculated using the Scherrer equation (3) (Scherrer 1912).

\section{See equation 3 in the supplementary files.}

Where, $\beta$ is the crystallite size perpendicular to the lattice plane represented by $(1-10), K$ is the Scherrer constant for a given crystal shape $(k=0.9), \lambda$ represents the wavelength of the incident $X$-rays $\left(1.54 \mathrm{~A}^{\circ}\right), L$ represents the width of the peak at half of its maximum, in radians (FWHM), and $\Theta$ is the position of the peak (half of the plotted $2 \Theta$ value) (French and Cintron 2013).

Thermal Properties

Thermal properties were examined using Thermogravimetric Analyzer (TGA) (Pyris1, PerkinElmer Inc., Shelton, CT, USA) under a nitrogen flow of $20 \mathrm{~mL} / \mathrm{min}$ and heating rate of $10^{\circ} \mathrm{C} / \mathrm{min}$ ranging from 37 to $600^{\circ} \mathrm{C}$. The thermograms were analyzed using Pyris software (version 11, PerkinElmer Inc., Shelton, CT, USA) (www.perkinelmer.com/product/s-w-kit-pyris-standard-single-user-n5340092) by calculating the first derivatives of the thermograms (DTG), weight loss percentage, and decomposition temperatures.

Statistical analysis

One-way analysis of variance (ANOVA) was performed with salts as a factor to determine the statistical difference between the means of the independent variables, for surface area tests and pore characteristics (diameter, density, total pore volume, and porosity). All the analyses were conducted using STATISTICA (Version 13, TIBCO Software Inc., Palo Alto, CA, USA)

(https://docs.tibco.com/products/tibco-statistica-13-3-0) at 95\% confidence interval (Cl). Three independent replications for each sample were performed.

\section{Results And Discussion}

Tendency of Cellulose Solution to Form Intact Monoliths in the Presence of Different Salts

In order to prepare a 'control' aerocellulose, dissolution of commercial MCC (5 wt.\%) in 7.6 wt.\% $\mathrm{NaOH}_{\mathrm{aq}}$ solvent system with no added salt was carried out through several freeze/thaw (F/T) cycles (see the Experimental Section for details (Dassanayake et al. 2016)), followed by gelation at $50^{\circ} \mathrm{C}$, solvent exchange and supercritical drying. Pure MCC solution yielded monoliths upon regeneration, indicated by the change in color of the cellulose gels from yellowish to white, and remained intact during subsequent processes until drying. Supercritically-dried control aerogels were white, and looked compact, with a smooth surface (Figure 1, left).

When the solid salts ( $0.5 \mathrm{wt}$ \% of $\mathrm{LiCl}, \mathrm{NaCl}, \mathrm{KCl}, \mathrm{MgCl}_{2}$, and $\mathrm{CaCl}_{2}$ ) were introduced to the polymer's solution prior to the gelation stage (see Experimental), and solutions were gelled and supercritically-dried in the same manner as the control, aerogels obtained with added salt were of the same white color. Despite the same amount of MCC used for the preparation, aerocelluloses prepared with added monovalent salts appeared bigger in size than the control sample, following the trend ACel-KCl > ACel- 
$\mathrm{NaCl}>\mathrm{ACel}$-LiCl > control (Fig. 1). Interestingly, the aerocellulose prepared with added $\mathrm{CaCl}_{2}$ looked somewhat bigger than the control and the one prepared with $\mathrm{MgCl}_{2}$ appeared comparable to the control (Fig. 1), and in terms of the size ACel- $\mathrm{CaCl}_{2}>\mathrm{ACel}-\mathrm{MgCl}_{2} \sim$ control. Aerogels prepared with added salt were somewhat less compact and were softer and weaker by pinch testing than the control.

Examining maximum amounts of solid salts $\left(\mathrm{LiCl}, \mathrm{NaCl}, \mathrm{KCl}, \mathrm{MgCl}_{2}\right.$, and $\left.\mathrm{CaCl}_{2}\right)$ that could be introduced to the polymer's solution prior to the gelation stage, we found out that each salt had its own concentration limit for producing a stable structure during regeneration, and showed different tendencies to form monoliths, see Table 1. The maximum salt concentration that could be incorporated into cellulose solutions and yielded strong monoliths upon regeneration and drying was increasing in the order: $\mathrm{CaCl}_{2}$ (1 wt.\%) $<\mathrm{MgCl}_{2}$ (3 wt.\%) $<\mathrm{KCl}(5 \mathrm{wt} . \%)<\mathrm{NaCl}(7 \mathrm{wt} . \%)<\mathrm{LiCl}(10 \mathrm{wt} . \%)$.

Though the cellulose gels with slightly higher salt load $\left(3 \mathrm{wt} . \% \mathrm{CaCl}_{2}, 5 \mathrm{wt} . \% \mathrm{MgCl}_{2}, 7 \mathrm{wt} . \% \mathrm{KCl}\right)$ remained intact during regeneration and drying, they were fragile and would break easily during handling and pinch testing. Cellulose gels with salt concentrations higher than the concentration limit could not be regenerated but were instead gradually "washed away" with water during several steps of solvent exchange; monoliths were never formed. (Note that the maximum attempted concentration for $\mathrm{LiCl}$ was $10 \mathrm{wt} \%$, that resulted in firm stable aerogel and no concentrations exceeding $10 \mathrm{wt} . \%$ was attempted.)

This trend shows that the tendency to form monolith decreased with an increase in cationic radii for monovalent and divalent salts following the order $\mathrm{Li}^{+}>\mathrm{Na}^{+}>\mathrm{K}^{+}$and $\mathrm{Mg}^{2+}>\mathrm{Ca}^{2+}$. The observed phenomenon directly corresponds to the Hofmeister series where the surface affinity of the cations decreases in the order $\mathrm{Li}^{+}>\mathrm{Na}^{+}>\mathrm{K}^{+}$and $\mathrm{Mg}^{2+}>\mathrm{Ca}^{2+}$ (Phan-Xuan et al. 2016). This suggests that a given volume of cellulose solution can hold a higher amount of monovalent salt compared to divalent salt. Moreover, it can also hold a higher amount of salts having a smaller cationic radius than a larger cationic radius without impacting its ability to form a monolith.

Table 1: Ability to form cellulose gels during regeneration in the presence of different salts 


\begin{tabular}{|c|c|c|c|c|c|c|}
\hline & $\begin{array}{l}\text { Salt } \\
\text { Concentration, } \\
\text { wt.\% }\end{array}$ & & & & & \\
\hline Salts & 0.5 & 1 & 3 & 5 & 7 & 10 \\
\hline $\mathrm{LiCl}$ & $t^{\mathrm{a}}$ & + & + & + & + & + \\
\hline $\mathrm{NaCl}$ & + & + & + & + & + & $+/-\mathrm{b}$ \\
\hline $\mathrm{KCl}$ & + & + & + & + & $+/-$ & - \\
\hline $\mathrm{MgCl}_{2}$ & + & + & + & $+/-$ & - & - \\
\hline $\mathrm{CaCl}_{2}$ & + & + & $+/-$ & $-c$ & - & - \\
\hline $\begin{array}{l}\text { a Monolith formed }(+)-\text { stable/strong monoliths } \\
\text { were obtained after drying; }{ }^{\text {b }} \text { Fragile monolith }( \pm)- \\
\text { stable structure was formed after regeneration but } \\
\text { was destroyed during drying; c Monolith did not form } \\
(-) \text { - cellulose did not form stable structure during } \\
\text { regeneration. }\end{array}$ & & & & & & \\
\hline
\end{tabular}

Such difference in the tendency of the solution to form a monolith could be due to the effect of the salt on the aggregation rate of the colloidal particles (Woehl et al. 2014). Salts with smaller cationic radii probably induced smaller aggregates than those with larger cationic radii and these aggregates are easily held together through extensive hydrogen bonding. In the latter case, larger-sized aggregates are formed which are difficult to hold together thereby negatively impacting the formation of a monolith during regeneration. Additionally, the difference in the cationic charge might have resulted in altered charge distribution in the solution and therefore, could alter their tendency to form monoliths (Wang et al. 2017). Overall, this showed that the size of component ions and their concentration in solution significantly affected the tendency of cellulose solution to form intact monolith.

Polarized light microscopy (PLM)

In order to establish whether the addition of salts to the $\mathrm{MCC}-\mathrm{NaOH}_{\mathrm{aq}}$ solution induced macroscale aggregation (precipitation) of cellulose, the $\mathrm{MCC}-\mathrm{NaOH}_{\mathrm{aq}}$ solutions with and without added salts were compared with each other and with MCC aqueous dispersion using PLM, see Fig. 2. As expected, clear differences were observed between cellulose dispersion and respective solutions because of the highly crystalline structure of native cellulose (Dissanayake et al. 2018). No bright particles or chunks were observed in cellulose solutions (both the pure cellulose and cellulose/salt solution mixtures) indicating that both cellulose and salts were mostly dissolved in $\mathrm{NaOH}_{\mathrm{aq}}$. However, as could be observed in PLM images, pure cellulose solution appeared clearer and more homogenous than the cellulose/salt solution mixtures. The latter appeared somewhat rougher with heterogeneous inclusions, more so for $\mathrm{Cel}-\mathrm{CaCl}_{2}$.

Effects of added salts on the sol-gel transition of the cellulose solution 
The effect of addition of metal salts on the polymer association in cellulose/ $\mathrm{NaOHaq}$ solutions and solgel transition was investigated using rheological measurements, by following the evolution of storage ( $\left.\mathrm{G}^{\prime}\right)$ and loss modulus ( $\left.G^{\prime \prime}\right)$. The maximum concentration that allowed the formation of monolith during regeneration for all salts used in the study was $1 \mathrm{wt} . \%$ (Table 1). However, since few cellulose solutions with $1 \%$ salt concentration formed gels immediately, solutions of smaller concentration, $0.5 \mathrm{wt} . \%$, were used for rheological (and all subsequent) studies. The critical gel point in relation to the salt types was determined using Winter and Chambon's theory (Winter and Chambon 1986), which states that the crossover point of storage modulus $\left(G^{\prime}\right)$ and loss modulus $\left(G^{\prime \prime}\right)$ represents the gel point (Tung and Dynes 1982).

The evolution of $\mathrm{G}^{\prime}$ and $\mathrm{G}^{\prime \prime}$ as a function of time for cellulose/salt solution at the constant $20^{\circ} \mathrm{C}$ temperature is shown in Fig. 3a. Overall, the pure cellulose solution (control) and cellulose/salt solutions displayed similar rheological behavior. Initially, the $G^{\prime}$ values of all solutions were smaller than the $G^{\prime \prime}$ values, indicating a viscous fluid behavior. With time, both $\mathrm{G}^{\prime}$ and $\mathrm{G}^{\prime}$ increased steadily, although the rate of increase was faster for G' than G". Eventually, G' intersected G", and the crossover point was observed indicating that the fluid has transitioned from fluid flow-like behavior to solid elastic behavior. This suggested that the sol-gel transition in pure cellulose solution and cellulose/salt solutions was a function of time and the system gradually transformed from a viscous liquid into an elastic network of cellulose chains forming a 3D-entangled polymeric network. The sol-gel transition of the cellulose solution indicated that the inclusion complex that was formed between cellulose and solvent molecules during the dissolution got broken, and hydrogen bonds between the polymer chains were re-established (Li et al. 2015).

The critical gel point of the pure cellulose solution was $1380 \mathrm{~s}$ at $20^{\circ} \mathrm{C}$, which was similar to the previously reported value ( 1200 s) for 5 wt.\% cellulose/8 wt.\% NaOHaq solution (Sescousse et al. 2011). Compared to the pure cellulose solution, the critical gel point of cellulose/salt solutions occurred at much shorter time (Table 2, Fig. 3a). Namely, the Cel-NaCl gelled in about $600 \mathrm{~s}, \mathrm{Cel}^{-\mathrm{CaCl}_{2}}$ in about $540 \mathrm{~s}$, Cel-

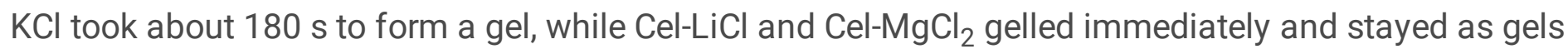
during the measurements (Fig. 3a). Furthermore, the initial G' and G" of the Cel- $\mathrm{MgCl}_{2}$ were of much higher values than for other solutions (Fig. 3b). This might have indicated stronger intermolecular forces and higher cellulose chain entanglement (Long et al. 2019) in the case of Cel- $\mathrm{MgCl}_{2}$. Overall, the critical gel point was found to follow the order: control $>$ Cel- $\mathrm{NaCl}>\mathrm{Cel}-\mathrm{CaCl}_{2}>\mathrm{Cel}-\mathrm{KCl}>\mathrm{Cel}-\mathrm{LiCl} \sim \mathrm{Cel}-\mathrm{MgCl}_{2}$. This supported earlier observation that salts had accelerating effect on the gelation, but came to be against earlier determined trend $\left(\mathrm{K}^{+}>\mathrm{Na}^{+}>\mathrm{Li}^{+}\right.$(Wei and Wang 2013)) likely due to the use of different solvent system.

It was also observed that the addition of salts slightly reduced the sol-gel transition temperature of the cellulose solution (Table 2, Fig. 3c). The pure cellulose solution gelled at about $27^{\circ} \mathrm{C}$, whereas all the cellulose/salt solution mixtures gelled at lower temperatures. Cel- $\mathrm{NaCl}$ and $\mathrm{CaCl}_{2}$ gelled at $24{ }^{\circ} \mathrm{C}$, followed by Cel- $\mathrm{LiCl}$ and Cel-KCl that gelled at $23^{\circ} \mathrm{C}$, and Cel- $\mathrm{MgCl}_{2}$ that gelled at $22^{\circ} \mathrm{C}$. 
Table 2: Gelation time and temperature of cellulose/salt solution mixtures and salts' cationic radii

\begin{tabular}{|llll|}
\hline & $\begin{array}{l}\text { Cationic radii (pm) (Shannon 1976; Ling et al. } \\
\text { 2013) }\end{array}$ & $\begin{array}{l}\text { Gelation Time } \\
(\mathbf{s})\end{array}$ & $\begin{array}{l}\text { Gelation Temperature } \\
\left({ }^{\circ} \mathbf{C}\right)\end{array}$ \\
\hline Control & 0 & 1380 & $\sim 27$ \\
\hline $\mathrm{Cel-LiCl}$ & 90 & 0 & $\sim 23$ \\
\hline $\begin{array}{l}\mathrm{Cel}- \\
\mathrm{NaCl}\end{array}$ & 116 & 560 & $\sim 24$ \\
\hline $\mathrm{Cel-KCl}$ & 152 & 159 & $\sim 23$ \\
\hline $\begin{array}{l}\mathrm{Cel}- \\
\mathrm{MgCl}_{2}\end{array}$ & 86 & 0 & $\sim 22$ \\
\hline $\begin{array}{l}\mathrm{Cel-} \\
\mathrm{CaCl}_{2}\end{array}$ & 114 & 519 & $\sim 24$ \\
\hline
\end{tabular}

Although this decrease in the sol-gel transition temperature due to salt addition was not significant, the strategy could be useful in applications where lowering of sol-gel transition temperature is desired, for instance, in drug delivery applications (Joshi 2011). It should be noted, however, that the hydrogels formed under these conditions (time and temperature) were fragile and could easily break under stress (Gavillon 2007). Therefore, during aerogel preparation, higher temperatures $\left(50^{\circ} \mathrm{C}\right)$ and longer time $(2 \mathrm{~h})$ were selected for gels formation to prepare stronger monoliths and avoid breakage during subsequent handling.

\section{Density and porosity}

Density and porosity values of cellulose aerogel monoliths as a function of salt treatments are shown in Fig. 4. It could be seen from the graphs that the addition of salts had a significant effect on both the density and porosity of aerogels, with density and porosity values inversely proportional to each other.

The control sample had a significantly lower porosity (88.3\%) than all other aerocelluloses. Among samples prepared with added salts, the porosity followed the trend (note that here ">"-sign indicated statistically significant difference): Cel- $\mathrm{KCl}(92.5 \%)>\mathrm{ACel}^{-\mathrm{CaCl}_{2}}$ (90.5\%) ACel-NaCl (90.3\%) ACel-LiCl $(90.1 \%) \sim ~ A C e l-M \mathrm{CCl}_{2}$ (89.4\%). The opposite trend was observed for density, with $\mathrm{ACel}-\mathrm{MgCl}_{2}$ possessing the highest density $\left(0.15 \mathrm{gm} / \mathrm{cm}^{3}\right)$, and ACel-KCl the lowest one $\left(0.11 \mathrm{gm} / \mathrm{cm}^{3}\right)$. The higher porosity achieved with added salt could be attributed to the restriction in the normal reorganization of cellulose chains due to the interaction between cellulose and cations of the salts in the solutions during the regeneration process.

Scanning Electron Microscopy (SEM) 
The internal morphology of the aerogels was studied by SEM. SEM images of the cross-sections of the monoliths are shown in Fig. 5. All aerogel samples exhibited porous structures with inner morphology strongly affected by salt addition. Control aerogel exhibited compact structure compared to more open porous structure for aerogels prepared with added salt. The latter group had a fine fibrillated texture, which gave aerogels a porous appearance of the cross-sections (Sescousse et al. 2011). Specifically, a denser arrangement of the fibrils and a higher number of smaller pores could be observed in $\mathrm{ACel}-\mathrm{MgCl}_{2}$ and $\mathrm{ACel}-\mathrm{LiCl}$, whereas more expansive open spaces were observed in $\mathrm{ACel-KCl}$ (see insets in Fig. 5); the pores of various sizes were observed in each of the samples (see cumulative pore volume, below).

The observed difference in the inner morphology could be attributed to the variation in the nature of the precursor sol induced by the addition of different salts. The nature of salts likely affected the properties of the cellulose solution which in turn influenced the phase separation process of the cellulose during regeneration and determined the micromorphology of the aerogels. The cellulose solution presumably underwent microphase separation during the gel formation leading to cellulose-poor and cellulose-rich phases (Gavillon and Budtova 2008). During the phase separation process, cellulose chains aggregated rapidly to form gels, and the presence of salt hydrates interfered with the normal aggregation process leading to differences in morphology.

Nitrogen adsorption-desorption isotherms

Comparative analysis of the effect of inorganic salts on the specific surface area and pore characteristics (cumulative pore volume, pore diameter, and pore size distribution) of cellulose aerogels were performed using gas sorption, which allowed construction of both adsorption and desorption isotherms with the measurement of Brunauer-Emmett-Teller (BET) surface area.

Two isotherms for cellulose aerogels (control and $\mathrm{ACel}-\mathrm{MgCl}_{2}$ ) are shown in Fig. 6. The isotherms obtained were of type IV with characteristic hysteresis loops at a high relative pressure caused by a capillary condensation in the pores, indicating a mesoporous nature of the aerogels. The specific surface area as a function of salt types compared to the control is shown in Fig. 7a. The surface area was found to be statistically larger for all aerogels prepared with added salts $\left(146-189 \mathrm{~m}^{2} / \mathrm{g}\right)$ than for the control $\left(118 \mathrm{~m}^{2} / \mathrm{g}\right)$. The specific surface area increased from $118 \mathrm{~m}^{2} / \mathrm{g}$ to $189 \mathrm{~m}^{2} / \mathrm{g}$ upon addition of $0.5 \mathrm{wt}$.\% $\mathrm{MgCl}_{2}$, followed by $\mathrm{LiCl}\left(177 \mathrm{~m}^{2} / \mathrm{g}\right), \mathrm{CaCl}_{2}\left(164 \mathrm{~m}^{2} / \mathrm{g}\right), \mathrm{NaCl}\left(153 \mathrm{~m}^{2} / \mathrm{g}\right)$, and $\mathrm{KCl}\left(146 \mathrm{~m}^{2} / \mathrm{g}\right)$ following the order $\mathrm{MgCl}_{2}>\mathrm{LiCl}>\mathrm{CaCl}_{2}>\mathrm{NaCl}>\mathrm{KCl}$ (Fig. 7a) which was consistent with the change in cationic radii.

The enhancement in the specific surface area could be attributed to the restriction in the normal reorganization of cellulose molecules due to the presence of cations. The cellulose interaction with the cations prevented the normal reorganization of cellulose chains during regeneration allowing cellulose to rearrange differently leading to differences in the specific surface area. The results showed that even though the addition of salts resulted in an increase of the specific surface area compared to the control in all cases, it was larger for aerogels prepared with salt having a lower cationic radius $\left(\mathrm{MgCl}_{2}\right.$ and $\left.\mathrm{LiCl}\right)$, and 
smaller for those with larger radii. The smaller surface area of ACel-KCl could be due to the large pore size because of their inverse relationship as reported in previous studies (Pei et al. 2014).

It is worth noting that the surface area of the aerogels was closely related to the gelation time. The cellulose solution with the longest gelation time yielded aerogels with the lowest surface area (i.e., control), whereas the shorter gelation time (Cel- $\mathrm{MgCl}_{2}$ and Cel- $\mathrm{LiCl}$ ) yielded a higher surface area aerogel. The change in the specific surface area is directly related to the change in the gelation time when a particular salt is added (Fig. 7e). With an increase in the gelation time, there was a gradual decrease in the specific surface area. The observed correlation between the gelation time and the specific surface area of aerogels could be rationalized by faster gel formation that gives less time for the cellulose macromolecules to get organized into an ordered structure. This might lead to aerogels with rough, porous structures, and higher surface area. Therefore, in this study the gelation time could be used as a predictor of the specific surface area.

\section{Cumulative Pore Volume}

Cumulative pore volume, the total volume of the pores, is another critical internal morphology characteristic of aerogels. The pore size was estimated from the isotherms of aerogels and ranged from a few $\mathrm{nm}$ to $\sim 50 \mathrm{~nm}$, demonstrating the presence of micro-, meso-, and macro-pores. The average pore size was the highest for ACel-KCl (ca. $25 \mathrm{~nm}$ ) and the lowest for ACel-LiCl (ca. $21 \mathrm{~nm}$ ). It was evident (Fig. 7b) that the cumulative pore volume was affected by salt types. The total pore volume was the highest for ACel- $\mathrm{MgCl}_{2}$, followed by ACel- $\mathrm{LiCl}, \mathrm{ACel}-\mathrm{KCl}, \mathrm{ACel}-\mathrm{NaCl}$, and Acel- $\mathrm{CaCl}_{2}$. The lower pore volume for ACel$\mathrm{KCl}$ could be attributed to bigger pore size and broader pore size distribution. In contrast, the salt with smaller pore size resulted in a higher total pore volume.

Powder X-ray Diffraction (pXRD)

To obtain a better understanding of the effect of salt particles on the cellulose crystalline structure, pXRD patterns of the aerogels with a series of salts were examined (Fig. 8).

In all cases, the pXRD patterns of aerogels revealed the presence of six major diffraction peaks at $2 \Theta$ values of $12^{\circ}, 20^{\circ}, 21.7^{\circ}, 28.5^{\circ}, 34.5^{\circ}$, and $40.9^{\circ}$, suggesting that cellulose existed in cellulose II crystalline form, thermodynamically more stable one, of lower crystallinity (Oh et al. 2005). Among these

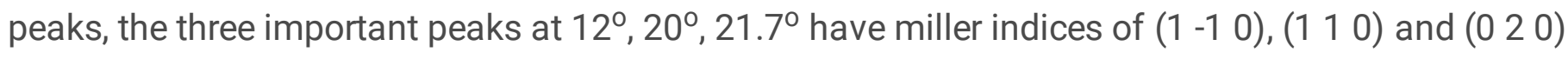
respectively (French 2014). There was no major difference between pXRD patterns of the aerogels prepared with the addition of different salts although some changes in the crystallinity index (CI) and the crystallite size were observed. It was found that the control samples were of the higher crystallinity and crystallite size. Similar values for crystallinity and crystallite size (for 1-1 0 peak) were reported previously for cellulose treated with $7.5 \% \mathrm{NaOH}$ (Nomura et al. 2020). Aerogels prepared from cellulose solutions with divalent salts have a lower $\mathrm{Cl}$ and crystallite size than those made with added monovalent salts. The crystallinity was proportional and the crystallite size inversely proportional to cationic radii for monovalent salts (Table 3). 
pXRD results corroborated the likely role of salts in preventing the formation of ordered cellulose domains or aggregates. The difference in $\mathrm{Cl}$ value for aerogels with different salts could be attributed to the variation in their cationic radii which determined the extent of interaction between salt hydrates and cellulose hydrates.

Table 3: Crystallinity index $(\mathrm{Cl})$ and the Crystallite size of the aerogels with different salts

\begin{tabular}{lcl} 
Aerogels & Cl (\%) & Crystallite size $(\mathrm{nm})$ \\
\hline Control & $\sim 74$ & 4.91 \\
\hline ACel- $\mathrm{LiCl}$ & $\sim 72$ & 4.74 \\
\hline ACel-NaCl & $\sim 72$ & 4.71 \\
\hline ACel-KCl & $\sim 73$ & 4.53 \\
\hline ACel- $-\mathrm{MgCl}_{2}$ & $\sim 71$ & 3.95 \\
\hline ACel-CaCl$_{2}$ & $\sim 71$ & 6.42
\end{tabular}

Thermal Gravimetric Analysis (TGA)

Further examination of different aerocelluloses was conducted by thermal gravimetric analysis (TGA). TGA curves and the thermogravimetric derivative (DTG) curves of the series of aerocelluloses are shown in Fig. 9. In all cases, TGA showed a two-steps decomposition, where $1^{\text {st }}$ step $\left(40-100{ }^{\circ} \mathrm{C}\right)$ was attributed to the removal of volatiles ( $7-9 \%$, traces of water and/or acetone), and the $2^{\text {nd }}$ decomposition step (ca. $240-450{ }^{\circ} \mathrm{C}$ ) was attributed to the disintegration of cellulose $(80 \%)$.

\section{Conclusions}

In this work, we studied the effect of the addition of various inorganic salts $\left(\mathrm{LiCl}, \mathrm{NaCl}, \mathrm{KCl}, \mathrm{MgCl}_{2}\right.$, and $\mathrm{CaCl}_{2}$ ) on the ability to form cellulose monoliths, sol-gel transition of cellulose solutions, and resulting aerocelluloses' morphology (porosity, density, specific surface area, total pore volume and pore size distribution). When $0.5 \mathrm{wt}$.\% of solid salts were introduced to the polymer's solution prior to gelation stage, the gelation ability increased (i.e., gels were formed faster and at lower temperature) but when the concentration reached or even exceeded a certain limit, different for different salts, the gelation ability declined. This maximum salt concentration that allowed monolith formation was higher for monovalent salts than for divalent salts. The rheological study showed that the sol-gel transition in pure cellulose solution and cellulose/salt solution mixture was a function of time and temperature. Compared to the pure cellulose solution, the critical gel point of cellulose/salt solutions occurred at much shorter time, with the smallest size cations $\left(\mathrm{Li}^{+}, \mathrm{Mg}^{2+}\right)$ taking place immediately, and with the largest size cations still proceeding at significantly faster rate following the order: Control $>\mathrm{Cel}-\mathrm{NaCl}>\mathrm{Cel}-\mathrm{CaCl}_{2}>\mathrm{Cel}-\mathrm{KCl}>\mathrm{Cel}-$ $\mathrm{LiCl} \sim \mathrm{Cel}-\mathrm{MgCl}_{2}$. 
The microarchitectural study showed that the porosity increased with the increase in cationic radii with the largest size cation inducing the highest porosity. The same was confirmed with SEM, where images showed that control aerogel exhibited more compact structure compared to a more open porous structure (with the presence of micro-, meso-, and macro-pores) for aerogels prepared with added salt, and the average pore size $20-25 \mathrm{~nm}$. The surface area was found to be statistically higher for all aerogels prepared with added salts $\left(146-189 \mathrm{~m}^{2} / \mathrm{g}\right)$ than for the control $\left(118 \mathrm{~m}^{2} / \mathrm{g}\right)$ following the order $\mathrm{MgCl}_{2}>$ $\mathrm{LiCl}>\mathrm{CaCl}_{2}>\mathrm{NaCl}>\mathrm{KCl}$. With the same concentration, salts with the lowest cationic radius $\left(\mathrm{MgCl}_{2}\right)$ yielded cellulose aerogels with $\sim 30 \%$ higher specific surface area than the salt with the highest cationic radius $(\mathrm{KCl})$.

pXRD analysis showed that the aerogels prepared from solutions with divalent salts had a lower crystallinity than those prepared with the assistance of monovalent salts, and all of aerogels were of lower crystallinity than aerogels prepared with no added salt (control). TGA analysis showed that aerogels with higher specific surface area showed $\sim 20^{\circ} \mathrm{C}$ improvement in the thermal stability than those with lower specific surface area. All of this shows that the physicochemical properties of aerogels could be tailored by using inorganic salts of specific properties.

\section{Declarations}

\section{Acknowledgments}

The authors would like to thank Dr. Bo Zhao of the College of Arts and Sciences Microscopy at Texas Tech University for her help in SEM images collection. Partial funding was provided by Cotton Incorporated and Texas State Support Committee.

\section{References}

Barrett EP, Joyner LG, Halenda PP (1951) The Determination of Pore Volume and Area Distributions in Porous Substances. I. Computations from Nitrogen Isotherms. J Am Chem Soc 73:373-380. https://doi.org/10.1021/ja01145a126

Brunauer S, Emmett PH, Teller E (1938) Adsorption of Gases in Multimolecular Layers. J Am Chem Soc 60:309-319. https://doi.org/10.1021/ja01269a023

Buchtová N, Budtova T (2016) Cellulose aero-, cryo- and xerogels: towards understanding of morphology control. Cellulose 23:2585-2595. https://doi.org/10.1007/s10570-016-0960-8

Budtova T, Navard P (2016) Cellulose in $\mathrm{NaOH}$ - water based solvents: a review. Cellulose 23:5-55. https://doi.org/10.1007/s10570-015-0779-8 
Cai J, Zhang L (2006) Unique gelation behavior of cellulose in $\mathrm{NaOH} /$ urea aqueous solution. Biomacromolecules 7:183-189. https://doi.org/10.1021/bm0505585

Chin SF, Jimmy FB, Pang SC (2016) Fabrication of cellulose aerogel from sugarcane bagasse as drug delivery carriers. J Phys Sci 27:159-168.

Dassanayake RS, Gunathilake C, Jackson T, et al (2016) Preparation and adsorption properties of aerocellulose-derived activated carbon monoliths. Cellulose 23:1363-1374. https://doi.org/10.1007/s10570-016-0886-1

Dissanayake N, Thalangamaarachchige VD, Troxell S, et al (2018) Substituent effects on cellulose dissolution in imidazolium-based ionic liquids. Cellulose 25:6887-6900. https://doi.org/10.1007/s10570018-2055-1

French AD (2014) Idealized powder diffraction patterns for cellulose polymorphs. Cellulose 21:885-896. https://doi.org/10.1007/s10570-013-0030-4

French AD, Cintron MS (2013) Cellulose polymorphy, crystallite size, and the segal crystallinity index. Cellulose 20:583-588. https://doi.org/10.1007/s10570-012-9833-y

Ganesan K, Barowski A, Ratke L, Milow B (2018a) Influence of hierarchical porous structures on the mechanical properties of cellulose aerogels. J Sol-Gel Sci Technol 89:156-165. https://doi.org/10.1007/s10971-018-4828-2

Ganesan K, Budtova T, Ratke L, et al (2018b) Review on the production of polysaccharide aerogel particles. Materials (Basel) 11:1-37. https://doi.org/10.3390/ma11112144

Ganesan K, Dennstedt A, Barowski A, Ratke L (2016) Design of aerogels, cryogels and xerogels of cellulose with hierarchical porous structures. Mater Des 92:345-355.

https://doi.org/10.1016/j.matdes.2015.12.041

Gavillon R (2007) Preparation and characterization of ultra porous cellulosic materials. Dissertation, École Nationale Supérieure des Mines de Paris

Gavillon R, Budtova T (2008) Aerocellulose: New highly porous cellulose prepared from cellulose- $\mathrm{NaOH}$ aqueous solutions. Biomacromolecules 9:269-277. https://doi.org/10.1021/bm700972k

Joshi SC (2011) Sol-gel behavior of hydroxypropyl methylcellulose (HPMC) in ionic media including drug release. Materials (Basel) 4:1861-1905. https://doi.org/10.3390/ma4101861

Kang KE, Park DH, Jeong GT, Jeong GT (2013) Effects of inorganic salts on pretreatment of Miscanthus straw. Bioresour Technol 132:160-165. https://doi.org/10.1016/j.biortech.2013.01.012 
Korhonen JT, Kettunen M, Ras RHA, Ikkala O (2011) Hydrophobic nanocellulose aerogels as floating, sustainable, reusable, and recyclable oil absorbents. ACS Appl Mater Interfaces 3:1813-1816. https://doi.org/10.1021/am200475b

Laka M, Chernyavskaya S, Klaviens Z et al (2001) Properties of microcrystalline cellulose gels formed in salt solutions. Cellul Chem Technol 35:409-416

Lazzari LK, Perondi D, Zampieri VB et al (2019) Cellulose/biochar aerogels with excellent mechanical and thermal insulation properties. Cellulose 26:9071-9083. https://doi.org/10.1007/s10570-019-02696-3

Li D, Wang Y, Sun Y et al (2018) Turning gelidium amansii residue into nitrogen-doped carbon nanofiber aerogel for enhanced multiple energy storage. Carbon 137:31-40.

https://doi.org/10.1016/j.carbon.2018.05.011

Li R, Wang S, Lu A, Zhang L (2015) Dissolution of cellulose from different sources in an $\mathrm{NaOH} / \mathrm{urea}$ aqueous system at low temperature. Cellulose 22:339-349. https://doi.org/10.1007/s10570-014-0542-6

Liao Q, Su X, Zhu W, et al (2016) Flexible and durable cellulose aerogels for highly effective oil/water separation. RSC Adv 6:63773-63781

Ling C, Chen J, Mizuno F (2013) First-principles study of alkali and alkaline earth ion intercalation in iron hexacyanoferrate: The important role of ionic radius. J Phys Chem C 117:21158-21165. https://doi.org/10.1021/jp4078689

Liu L, Sun J, Cai C, et al (2009) Corn stover pretreatment by inorganic salts and its effects on hemicellulose and cellulose degradation. Bioresour Technol 100:5865-5871. https://doi.org/10.1016/j.biortech.2009.06.048

Long LY, Li FF, Weng YX, Wang YZ (2019) Effects of sodium montmorillonite on the preparation and properties of cellulose aerogels. Polymers (Basel) 11:1-10. https://doi.org/10.3390/polym11030415

Long LY, Weng YX, Wang YZ, Wang YZ (2018) Cellulose aerogels: Synthesis, applications, and prospects. Polymers (Basel) 8:1-28. https://doi.org/10.3390/polym10060623

Luo X, Zhang $L$ (2010) Creation of regenerated cellulose microspheres with diameter ranging from micron to millimeter for chromatography applications. J Chromatogr A 1217:5922-5929.

https://doi.org/10.1016/j.chroma.2010.07.026

Nam S, French AD, Condon BD, Concha M (2016) Segal crystallinity index revisited by the simulation of Xray diffraction patterns of cotton cellulose I $\beta$ and cellulose II. Carbohydr Polym 135:1-9. https://doi.org/10.1016/j.carbpol.2015.08.035

Nomura S, Kugo Y, Erata T (2020) ${ }^{13} \mathrm{C}$ NMR and XRD studies on the enhancement of cellulose II crystallinity with low concentration NAOH post-treatments. Cellulose 27:3553-3563. 
Oğuz OD, Ege D (2018) Rheological and mechanical properties of thermoresponsive methylcellulose/calcium phosphate-based injectable bone substitutes. Materials (Basel) 11. https://doi.org/10.3390/ma11040604

Oh SY, Dong IY, Shin Y, et al (2005) Crystalline structure analysis of cellulose treated with sodium hydroxide and carbon dioxide by means of X-ray diffraction and FTIR spectroscopy. Carbohydr Res 340:2376-2391. https://doi.org/10.1016/j.carres.2005.08.007

Parajuli P, Acharya S, Hu Y, Abidi N (2020) Cellulose-based monoliths with enhanced surface area and porosity. J Appl Polym Sci 137:48975. https://doi.org/10.1002/app.48975

Park S, Baker JO, Himmel ME, et al (2010) Cellulose crystallinity index: measurement techniques and their impact on interpreting cellulase performance. Biotechnol Biofuels 3:10. https://doi.org/10.1186/17546834-3-10

Pei X, Zhai W, Zheng W (2014) Preparation and characterization of highly cross-linked polyimide aerogels based on polyimide containing trimethoxysilane side groups. Langmuir 30:13375-13383. https://doi.org/10.1021/la5026735

Phan-Xuan T, Thuresson A, Skepö M, et al (2016) Aggregation behavior of aqueous cellulose nanocrystals: the effect of inorganic salts. Cellulose 23:3653-3663. https://doi.org/10.1007/s10570-0161080-1

Pircher N, Carbajal L, Schimper C, et al (2016) Impact of selected solvent systems on the pore and solid structure of cellulose aerogels. Cellulose 23:1949-1966. https://doi.org/10.1007/s10570-016-0896-z

Pircher N, Fischhuber D, Carbajal L et al (2015) Preparation and Reinforcement of Dual-Porous Biocompatible Cellulose Scaffolds for Tissue Engineering. Macromol Mater Eng. 300:911-924. https://doi.org/10.1002/mame.201500048

Santos-Rosales V, Ardao I, Alvarez-Lorenzo C, et al (2019) Sterile and dual-porous aerogels scaffolds obtained through a multistep supercritical $\mathrm{CO}_{2}$-based approach. Molecules 24:871. https://doi.org/10.3390/molecules24050871

Scherrer P (1912) Bestimmung der inneren Struktur und der Größe von Kolloidteilchen mittels Röntgenstrahlen. In: Kolloidchemie Ein Lehrbuch. Springer, Berlin, pp 387-409

Schestakow M, Karadagli I, Ratke L (2016a) Cellulose aerogels prepared from an aqueous zinc chloride salt hydrate melt. Carbohydr Polym 137:642-649. https://doi.org/10.1016/j.carbpol.2015.10.097

Schestakow M, Muench F, Reimuth C et al (2016b) Electroless synthesis of cellulose-metal aerogel composites. Appl Phys Lett 108:213108. https://doi.org/10.1063/1.4952948 
Segal L, Creely JJ, Martin AE, Conrad CM (1959) Empirical Method for Estimating the Degree of Crystallinity of Native Cellulose Using the X-Ray Diffractometer. Textile Res J 29:786-794 https://doi.org/10.1177/004051755902901003

Sehaqui H, Zhou Q, Berglund LA (2011) High-porosity aerogels of high specific surface area prepared from nanofibrillated cellulose (NFC). Compos Sci Technol 71:1593-1599.

https://doi.org/10.1016/j.compscitech.2011.07.003

Sescousse R, Gavillon R, Budtova T (2011) Wet and dry highly porous cellulose beads from cellulose$\mathrm{NaOH}$-water solutions: Influence of the preparation conditions on beads shape and encapsulation of inorganic particles. J Mater Sci 46:759-765. https://doi.org/10.1007/s10853-010-4809-5

Shannon RD (1976) Revised effective ionic radii and systematic studies of interatomic distances in halides and chalcogenides. Acta Crystallogr Sect A 32:751-767.

https://doi.org/10.1107/S0567739476001551

Soorbaghi FP, Isanejad M, Salatin S et al (2019) Bioaerogels: Synthesis approaches, cellular uptake, and the biomedical applications. Biomed Pharmacother 111:964-975.

https://doi.org/10.1016/j.biopha.2019.01.014

Tian J, Peng D, Wu X, et al (2017) Electrodeposition of Ag nanoparticles on conductive polyaniline/cellulose aerogels with increased synergistic effect for energy storage. Carbohydr Polym 156:19-25. https://doi.org/10.1016/j.carbpol.2016.09.005

Tokuyasu K, Tabuse M, Miyamoto M et al (2008) Pretreatment of microcrystalline cellulose flakes with $\mathrm{CaCl}_{2}$ increases the surface area, and thus improves enzymatic saccharification. Carbohydr Res 343:1232-1236. https://doi.org/10.1016/j.carres.2008.03.007

Tung CYM, Dynes PJ (1982) Relationship between viscoelastic properties and gelation in thermosetting systems. J Appl Polym Sci 27:569-574. https://doi.org/10.1002/app.1982.070270220

Wan C, Jiao Y, Sun Q, Li J (2016) Preparation, characterization, and antibacterial properties of silver nanoparticles embedded into cellulose aerogels. Polym Compos 37:1137-1142.

https://doi.org/https://doi.org/10.1002/pc.23276

Wang X, Zhang Y, Jiang H et al (2017) Tert-butyl alcohol used to fabricate nano-cellulose aerogels via freeze-drying technology. Mater Res Express 4:065006. https://doi.org/10.1088/2053-1591/aa72bc

Wei Z, Wang T (2013) Preparation of cellulose aerogel by the salt-induced gelation. Chinese J Process Eng 13:351-355.

Winter HH, Chambon F (1986) Analysis of Linear Viscoelasticity of a Crosslinking Polymer at the Gel Point. J Rheol 30:367-382. https://doi.org/10.1122/1.549853 
Woehl TJ, Heatley KL, Dutcher CS et al (2014) Electrolyte-dependent aggregation of colloidal particles near electrodes in oscillatory electric fields. Langmuir 30:4887-4894. https://doi.org/10.1021/la4048243

Zhang XF, Ma X, Hou T et al (2019) Inorganic Salts Induce Thermally Reversible and Anti-Freezing Cellulose Hydrogels. Angew Chemie - Int Ed 58:7366-7370. https://doi.org/10.1002/anie.201902578

\section{Figures}

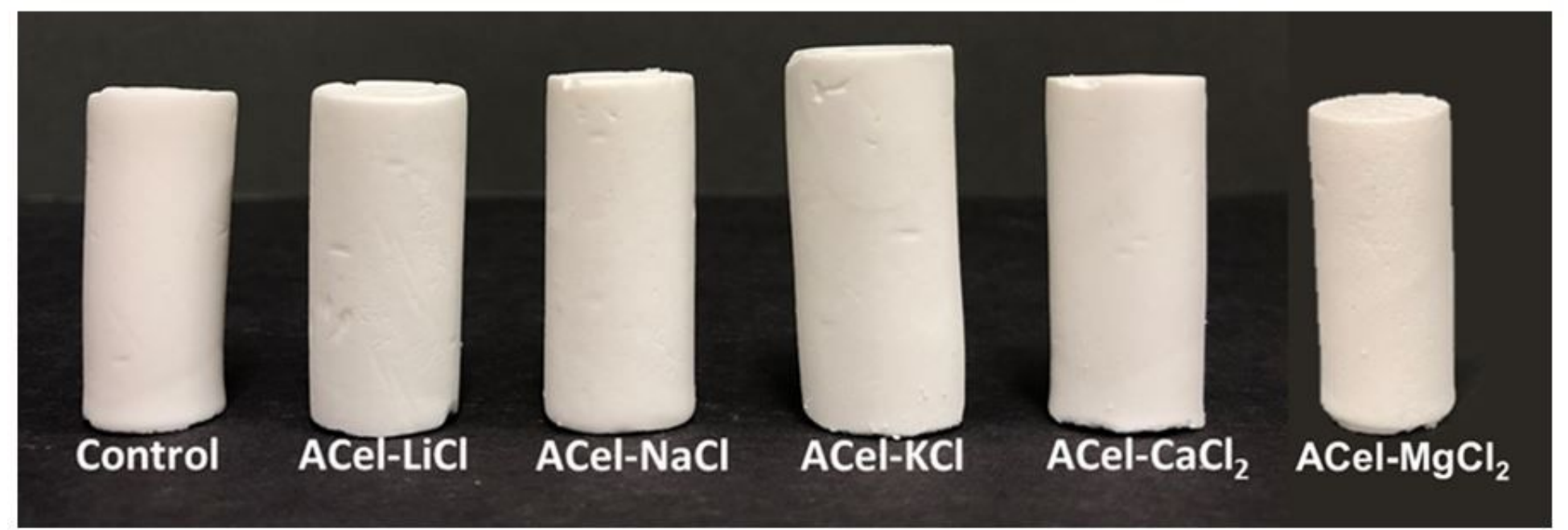

\section{Figure 1}

Cellulose aerogels developed without salt (control) and with salts (note increase in all dimensions with an increase of cationic radii)
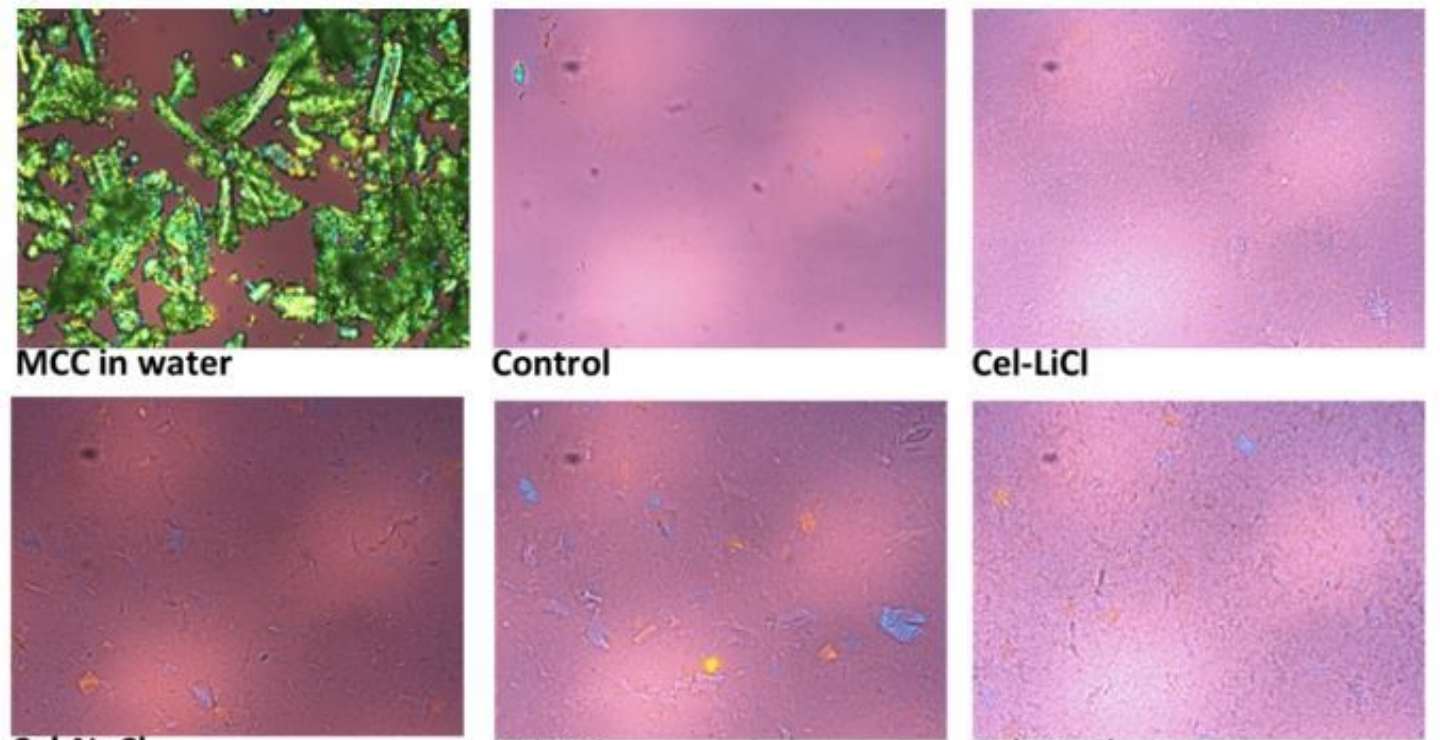

Cel-NaCl
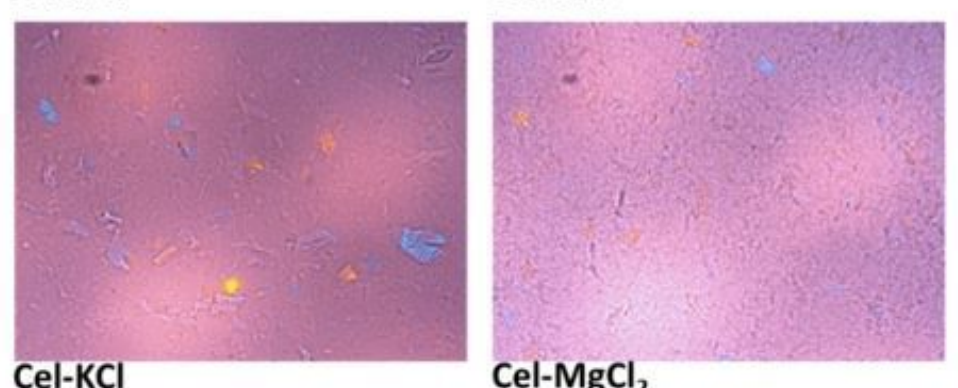

Cel-MgCl

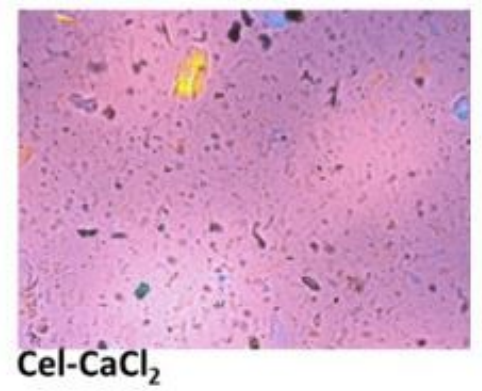

Figure 2 
PLM images of MCC dispersion, cellulose solution, and cellulose/salt (0.5\%) mixture solution after 10 min of adding salt (Magnification: $x 10$, salt concentration: $0.5 \%$ )
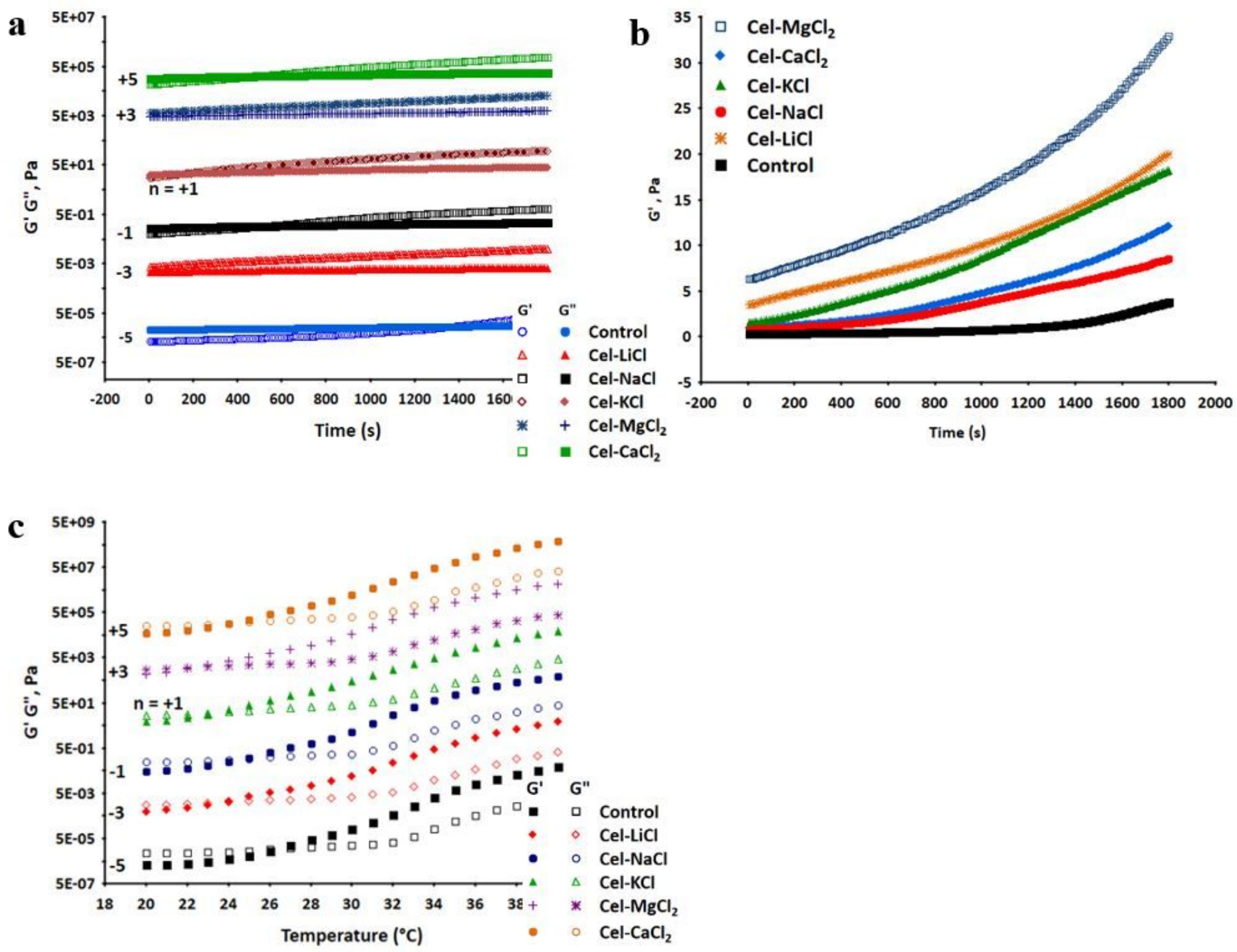

\section{Figure 3}

Effect on salt types on the sol-gel transition of cellulose solution: a) time sweep test, b) evolution of G' as a function of salt types, c) temperature sweep test. The data are shifted along the vertical axis by $10 \mathrm{n}$ to avoid overlapping in a) and c). 

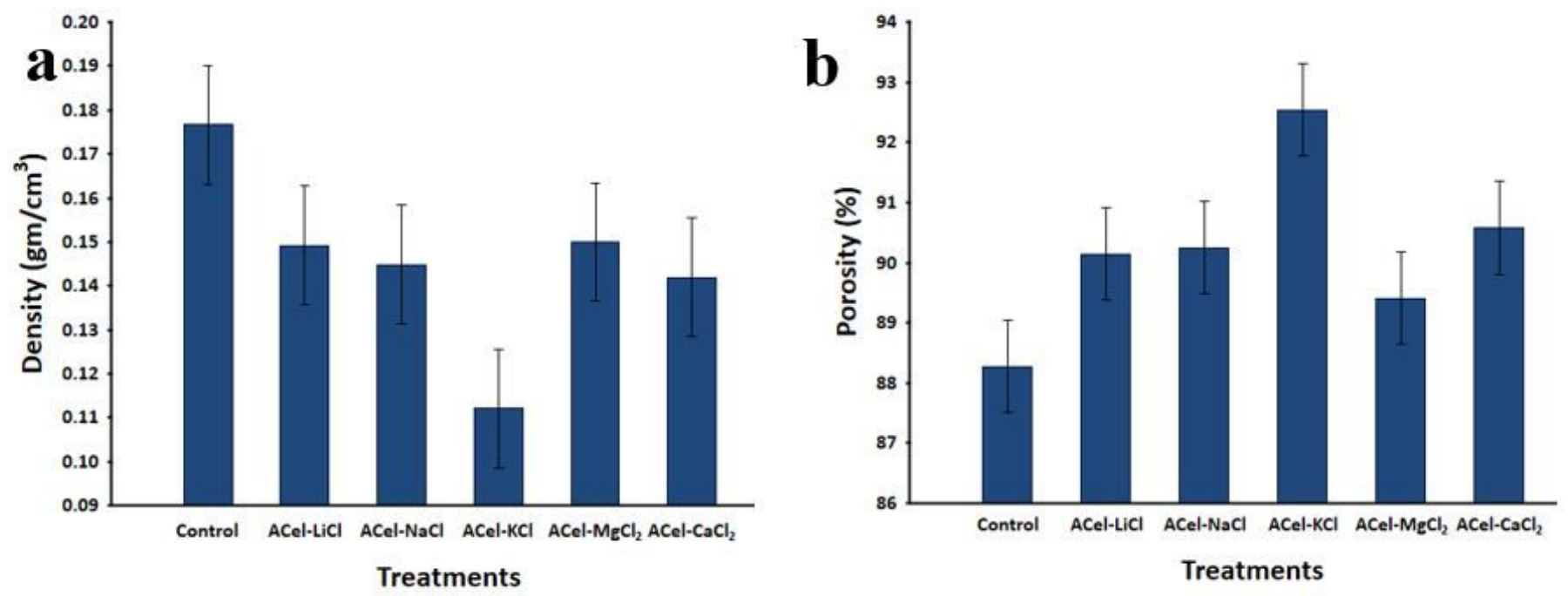

Figure 4

Effect of salts on the density and porosity of aerocelluloses: a) density and b) porosity of cellulose aerogels.

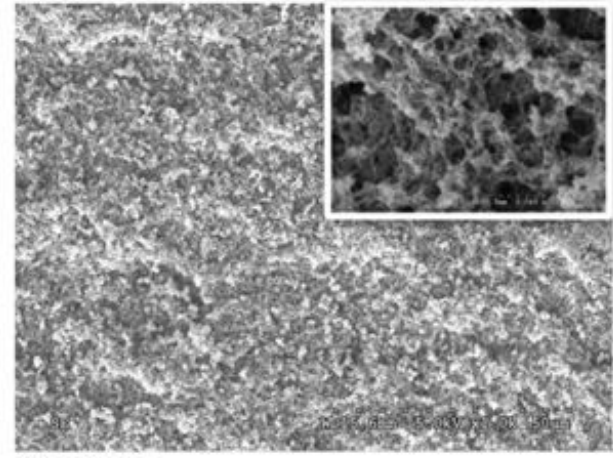

Control

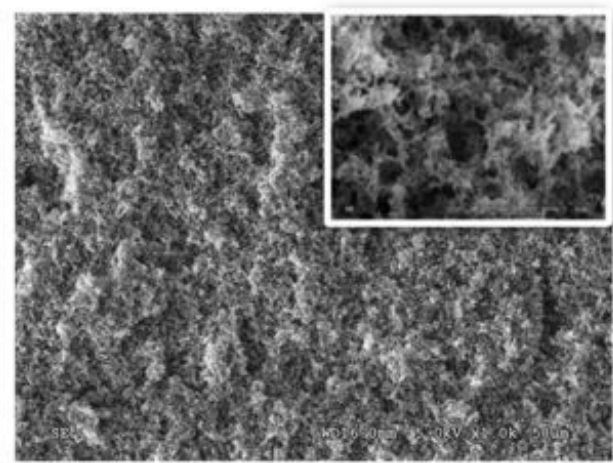

ACel-KCl

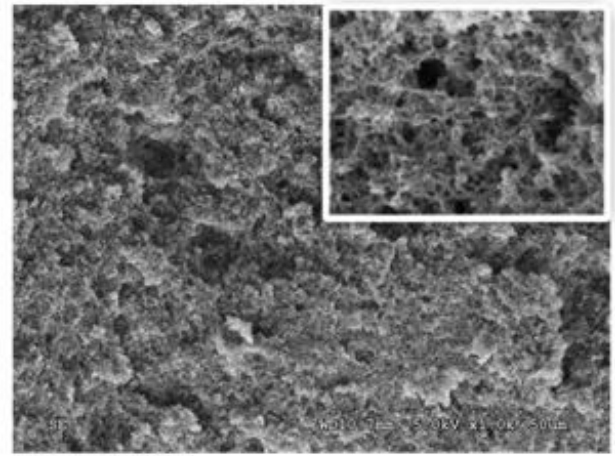

ACel-LiCl

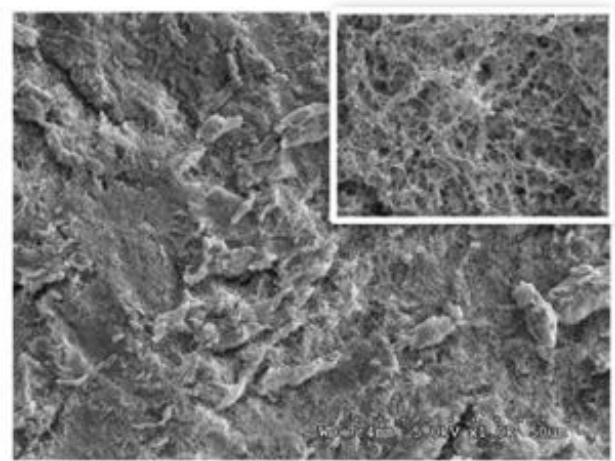

ACel- $\mathrm{MgCl}_{2}$

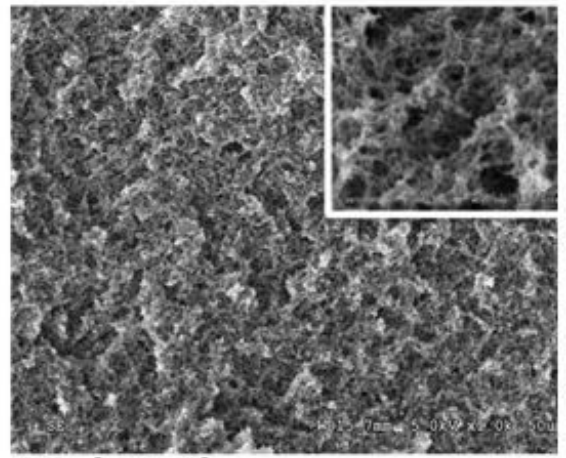

ACel-NaCl



ACel- $\mathrm{CaCl}_{2}$

\section{Figure 5}

SEM images of the cross-section of cellulose aerogels (magnification $x 1000$, inset: magnification $\mathrm{x} 20000)$ 

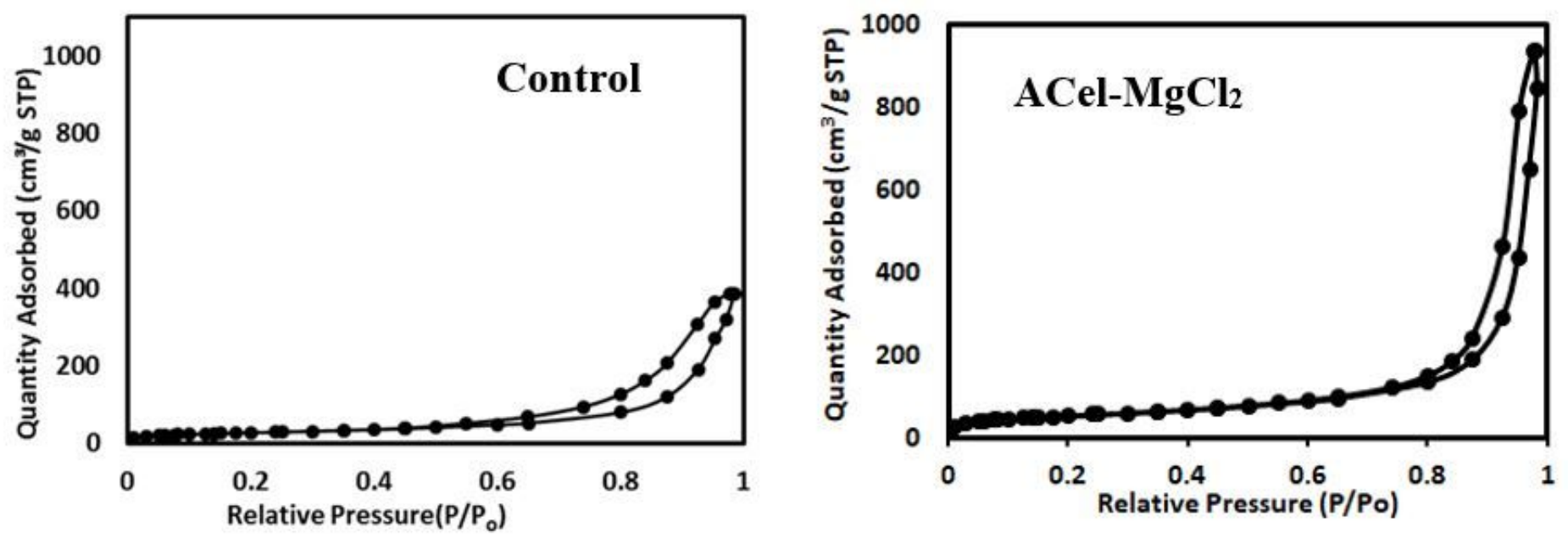

Figure 6

N2 adsorption-desorption isotherms of aerogels (left: Control, right: ACel-MgCl2) 
a
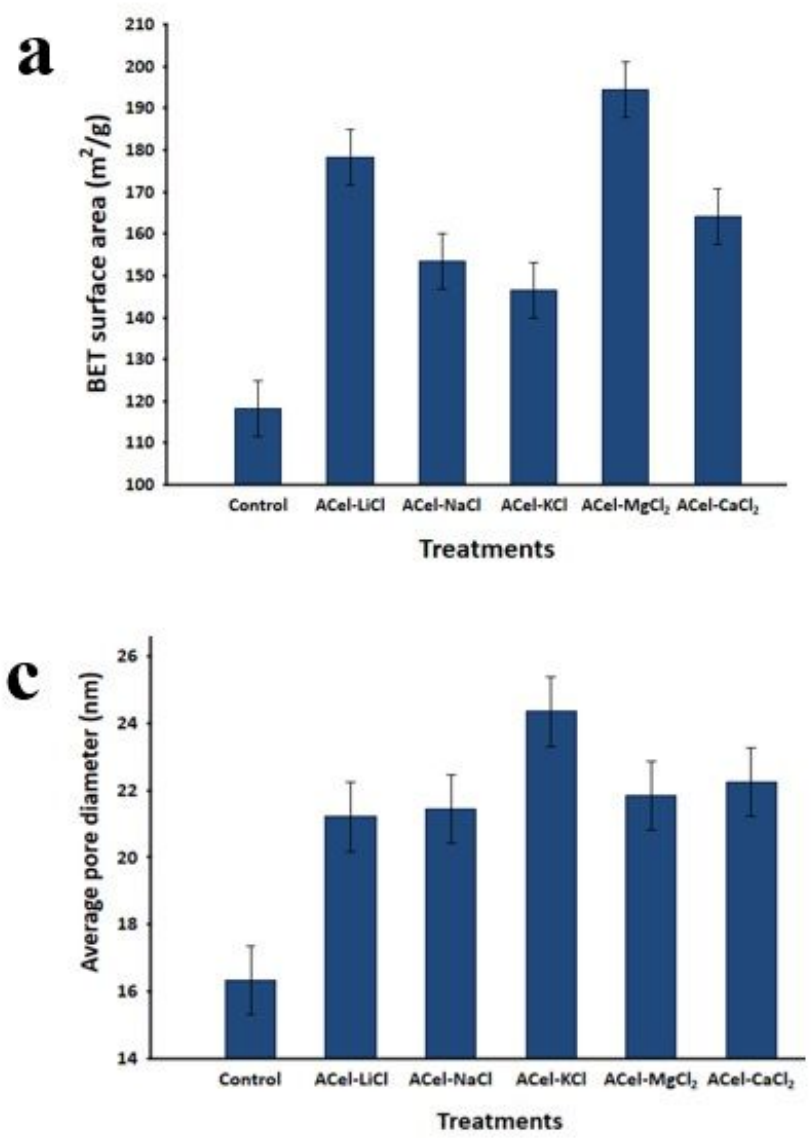

e

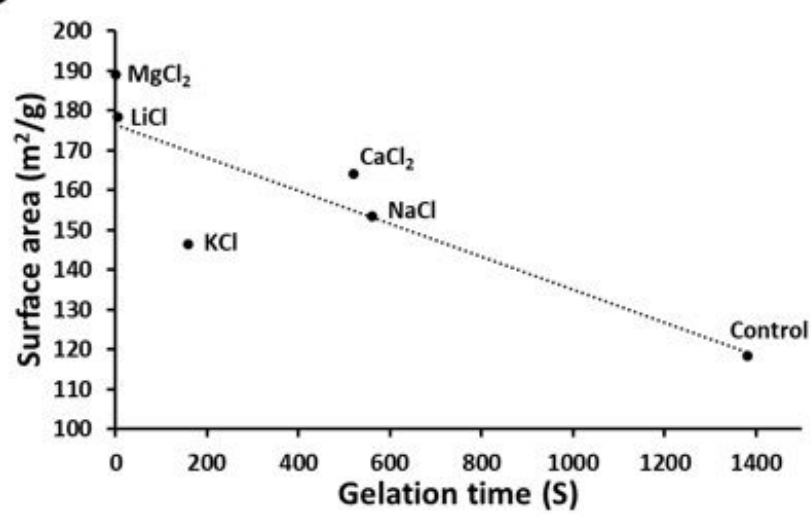

b

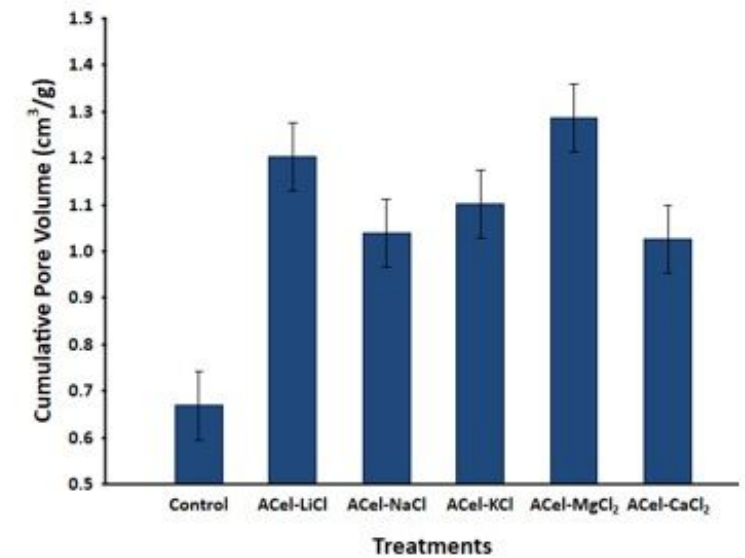

d

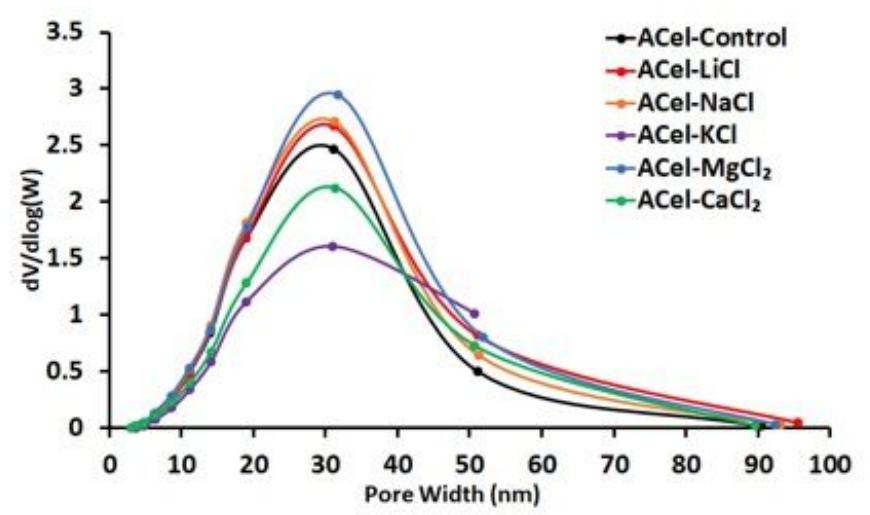

\section{Figure 7}

Effect of salt on a) BET surface area, b) cumulative pore volume, c) average pore diameter of cellulose aerogels, d) pore size distribution, e) relationship between the surface area and gelation time for different salts. 


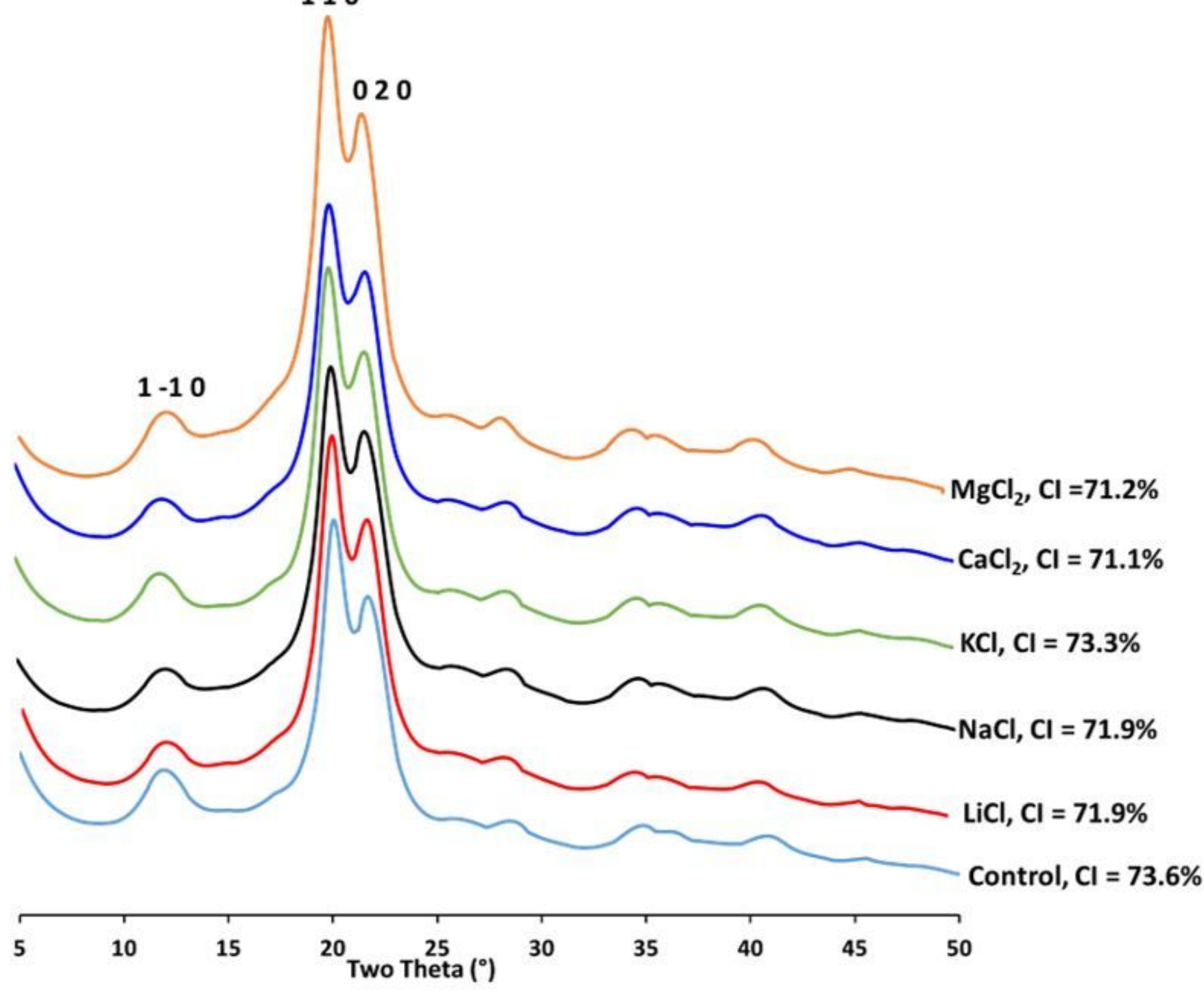

Figure 8

pXRD pattern of the aerogels with different salts



\section{Figure 9}

TGA thermograms of cellulose aerogels. a) TGA curves and b) DTG curves of aerogels with different salt particlesTGA thermograms of cellulose aerogels showed that all salt-assisted aerogels displayed better thermal stability than the control. Namely, the aerocelluloses ACel- $\mathrm{LiCl}$ and $\mathrm{ACel}-\mathrm{MgCl} 2$ exhibited the highest decomposition temperature (369 and 366 oC, respectively) followed by ACel-CaCl2 (361 oC), ACel$\mathrm{NaCl}(354 \mathrm{oC}), \mathrm{ACel}-\mathrm{KCl}(351 \mathrm{oC})$, and finally control (349 oC). Overall, the data showed that for both monovalent salts and divalent salts, lower cationic radii imparted better thermal stability to the aerocellulose. 